\title{
Specific immunotherapy downregulates peripheral blood CD4 and CD8 T-lymphocyte activation in grass pollen-sensitive asthma
}

\author{
M. Majori*, S. Bertacco*, M.L. Piccoli*, R. Melej', V. Pileggi++, A. Pesci*
}

Specific immunotherapy downregulates peripheral blood CD4 and CD8 T-lymphocyte activation in grass pollen-sensitive asthma. M. Majori, S. Bertacco, M.L. Piccoli, R. Melej, V. Pileggi, A. Pesci. COERS Journals Ltd 1998.

ABSTRACT: Several lines of evidence indicate that specific immunotherapy may act by modifying the immune responses of T-lymphocytes to the antigen.

To evaluate the effect of specific immunotherapy on the activation of T-lymphocytes by cluster of differentiation cells (CD4+ and CD8+) in peripheral blood, the expression of two surface activation markers, the p55 interleukin-2 receptor $(\mathrm{CD25})$ and human leucocyte antigen (HLA)-DR, was studied prospectively on circulating CD4+ and CD8+ T-cell subsets in subjects with grass-pollen sensitive asthma before and after $1 \mathrm{yr}$ of treatment with specific immunotherapy. Twenty five asthmatic patients with pollen sensitivity other than grass, studied out of their pollen season, served as the control group.

Specific immunotherapy improved clinical indices of disease activity including symptom scores and medication use during the pollen season of the treatment year. It had a marked effect in reducing the expression of the two activation markers, CD25 and HLA-DR, in both CD4+ $(p=0.002$ and $p=0.005$, respectively $)$ and CD8+ $(p=0.01$ and $p=0.01$, respectively) $T$-cell subsets, in parallel with a significant decrease in CD23 expression on B-cells $(p=0.008)$ and in grass-specific immunoglobulin $E$ levels $(p=0.01)$ in the peripheral blood of subjects with grass pollen-sensitive asthma. The decreased T-lymphocyte activation observed in immunotherapy-treated subjects after the treatment year was significant $(p=0.05)$ in comparison with the control group.

These data add to the view that the efficacy of specific immunotherapy may be attributed to the downregulation of T-cell responses.

Eur Respir J 1998; 11: 1263-1267.
*Istituto di Clinica delle Malattie dell'Apparato Respiratorio dell'Università degli Studi, Parma, Italy. ${ }^{+}$Azienda Ospedaliera and ${ }^{++}$Azienda Unità Sanitaria Locale di Parma, Italy.

Correspondence: A. Pesci

Istituto di Clinica delle Malattie Apparato Respiratorio

Via Rasori no. 10

43100 Parma

Italy

Fax: 39521292615

Keywords: Asthma

atopy

peripheral blood lymphocytes

specific immunotherapy

Received: November 31997

Accepted after revision March 11998

Partially supported by a grant from Ministero dell'Università, Ricerca Scientifica e Tecnologica, Italy.
Although specific immunotherapy (SIT) has been used for the treatment of allergic bronchial asthma since 1911, its exact mechanism has not yet been completely clarified [1].

Several immunological changes occur during SIT that may contribute to its efficacy. These include an increase in allergen-specific immunoglobulin ( $\mathrm{Ig}) \mathrm{G}$ antibodies [2] and moderate impairment in the synthesis of allergen-specific IgE [3], development of anti-idiotypic antibodies [4], re-duced basophil reactivity and sensitivity to allergens [2], reduced allergen-stimulated lymphocyte proliferation and lymphokine production [5, 6], and the generation of allergen-specific suppressor T-cells [7].

Recently, it has been suggested that SIT alters the balance of cytokines released from helper T-lymphocytes in the respiratory tract, with a shift from the type 2 helper $\mathrm{T}$ (Th2)-cells, which release interleukin (IL)-4 and IL-5 in association with allergic inflammation, towards type 1 hel-per $\mathrm{T}$ (Th1)-cells that release interferon- $\gamma$, which inhibits Th2 cells $[8,9]$.

There is increasing evidence that the bronchial inflammation characteristic of asthma represents a specialized form of cell-mediated immunity in which lymphokine products of the Th2 cells orchestrate the accumulation and activation of granulocytes. Of these, eosinophils are particularly implicated in causing the damage to the bronchial mucosa that is thought to underlie the clinical manifestation of asthma [10].

Although T-cell attraction and activation in the bronchial compartment is most evident in asthma, signs of activation of T-cells in the peripheral blood can also be measured. In acute severe [11] and moderate-to-severe [12] asthma, Tlymphocyte activation in peripheral blood has been shown to relate to the clinical expression of the disease, as reflected by the increase of cluster of differentiation (CD4+) Tlymphocytes activated in peripheral blood, and the ability to reduce this with parenteral or oral corticosteroids, respectively, in parallel with clinical improvement.

Little information is available on the possible changes following SIT in T-lymphocytes activation in peripheral blood from asthmatic subjects $[13,14]$.

The aim of the present study was to evaluate this effect on CD4+ and CD8+ T-cell subsets. For this purpose we examined the expression of two surface activation markers, the $\alpha$-chain (Tac) of the IL-2 receptor (CD25) and the class II major histocompatibility complex antigen human leucocyte antigen (HLA)-DR, on circulating CD4+ and CD8+ T-cell subsets from subjects with grass pollen-sensitive asthma before and after $1 \mathrm{yr}$ of SIT. The control group comprised 25 asthmatic patients with pollen sensitivity other than grass studied out of their pollen season. 


\section{Materials and methods}

\section{Study subjects}

A group of 12 subjects with grass pollen-sensitive asthma (eight males and four females, aged 25.4 $\pm 1.65 \mathrm{yrs}$ (mean \pm SEM) range 19-37 yrs) living in the Parma area were enrolled in this study. Characteristics of the immunotherapy-treated patients are shown in table 1. As a control group, 25 asthmatic subjects with pollen sensitivity other than grass (11 Betulaceae, six Corylaceae, six Urticaceae and two Compositae) (13 males and 12 females, mean age $31.5 \pm 1.7 \mathrm{yrs}$, range $21-40 \mathrm{yrs}$ ) and disease of comparable severity (when compared with immunothe-rapy-treated patients before they had received treatment) were recruited from the outpatient clinic of the Rasori Hospital, Parma.

All patients fulfilled the criteria of the American Thoracic Society [15] for the diagnosis of asthma, and they all had clinical histories of bronchospasm after pollen exposure. The diagnosis was confirmed by a positive skin test with pollen extracts, total serum IgE levels $>100 \mathrm{U} \cdot \mathrm{mL}^{-1}$ and the presence of allergen-specific IgE, scored from 0 to 4 (DHS CLA Allergy Test; Bayer, Milan, Italy). No patient had perennial allergy.

Patients requiring theophylline, anticholinergic, inhaled or oral corticosteroids, long-acting inhaled bronchodilators, oral bronchodilators and antihistamines were excluded from the study. Respiratory symptoms during the pollen season in immunotherapy-treated patients were controlled with inhaled short-acting bronchodilators (salbutamol) on a continuous basis or on demand.

Patients presenting with at least one of the following conditions: chronic asthma, asthma requiring one or more hospitalizations in the previous year, current smoking, previous treatment with SIT, systemic illness or pregnancy, were also excluded. Each subject gave informed and signed consent to participate in the study.

\section{Study design}

After selection, all subjects with grass pollen-sensitive asthma were monitored during the 1993 pollen season
(P0) (from April 15-May 31) before the beginning of SIT. Patients were asked to keep a diary in which they recorded: 1) symptoms of asthma according to a $0-3$ grading (0: absent, 1: mild, 2: moderate, 3: severe); 2) number of puffs $(100 \mu \mathrm{g})$ per day of salbutamol required to control symptoms; and 3) peak expiratory flow (PEF) as the best of three pretreatment measurements taken twice daily using a mini-Wright portable peak flow meter (Markos, Italy). From October 1993 to October 1994 each subject was submitted to SIT with an aluminium hydroxide-absorbed grass pollen extract (Bayer, Milan Italy). The dose scheduled was administered subcutaneously and was similar in all subjects. The initial dose was 2.5 activity units $(\mathrm{AU})$ of alpha fraction (200 AU = skin activity reference allergen/histamine $1 \%$ (SARAH)), and it was first increased weekly up to a maintenance dose of 800 AU. The maintenance dose was reached after approximately 3 months, and then this dose was administered every 2 weeks for 1 month and thereafter every 4 weeks. During the pollen sea-son, the dosages were lowered to $40-60 \%$ of the maximum amount reached. Patients underwent pulmonary function testing, i.e. the forced expiratory volume in one second (FEV1) and methacholine sensitivity (provocative concentration of methacholine causing a $20 \%$ fall in FEV1; PC20) (Spiroflow; Morgan, Kent, UK), and a peripheral venous blood sample was taken for lymphocyte subset analyses and measurements of grass-specific IgE levels before the beginning of SIT (T0, October 1993) and following $1 \mathrm{yr}$ of treatment (T1, October 1994). During the 1994 pollen season (P1) all patients were monitored for symptoms, salbutamol consumption and PEF, according to the criteria already given for P0. Grass pollen counts for the two pollen seasons were obtained from Agenzia Regionale per la prevenzione e l'ambiente dell'Emilia, Romagna, Sezione Provinciale di Parma.

The control group was sampled once only, out of their pollen season.

\section{Analysis of lymphocytes}

Specific binding of monoclonal antibodies (mAB) was analysed by direct immunofluorescence according to standard methods recommended by Becton-Dickinson Monoclonal Center (Mountain View, CA, USA) using a flow

Table 1. - Characteristics of the immunotherapy-treated patients

\begin{tabular}{|c|c|c|c|c|c|c|c|}
\hline $\begin{array}{l}\text { Patient } \\
\text { number }\end{array}$ & $\begin{array}{l}\text { Age } \\
\text { yrs }\end{array}$ & Sex & $\begin{array}{l}\text { Total IgE } \\
\text { IU } \cdot \mathrm{mL}^{-1}\end{array}$ & $\begin{array}{c}\text { Grass-specific } \\
\text { IgE* } \\
\text { Score } 0-4\end{array}$ & $\begin{array}{l}\text { Skin test } \\
\text { Score } 0-4\end{array}$ & $\begin{array}{l}\text { FEV1 } \\
\% \text { pred }\end{array}$ & $\begin{array}{c}\mathrm{PC}_{20} \\
\mathrm{mg} \cdot \mathrm{mL}^{-1}\end{array}$ \\
\hline 1 & 23 & $\mathrm{~F}$ & 800 & 4 & 4 & 120 & 4.9 \\
\hline 2 & 25 & M & 250 & 3 & 4 & 117 & 6.7 \\
\hline 3 & 21 & M & 1000 & 4 & 4 & 102 & 6.1 \\
\hline 4 & 21 & $\mathrm{~F}$ & 1000 & 4 & 3 & 91 & 3.0 \\
\hline 5 & 33 & $\mathrm{~F}$ & 600 & 4 & 4 & 99 & 1.1 \\
\hline 6 & 28 & $\mathrm{~F}$ & 160 & 4 & 4 & 111 & 4.6 \\
\hline 7 & 37 & M & 900 & 4 & 4 & 90 & 7.8 \\
\hline 8 & 28 & M & 150 & 3 & 4 & 90 & 8.0 \\
\hline 9 & 19 & M & 300 & 4 & 4 & 97 & 8.0 \\
\hline 10 & 20 & M & 600 & 3 & 3 & 99 & 0.3 \\
\hline 11 & 23 & M & 300 & 4 & 3 & 89 & 1.4 \\
\hline 12 & 26 & M & 200 & 3 & 4 & 90 & 8.0 \\
\hline
\end{tabular}

M: male; F: female; IgE: immunoglobulin E; FEV1: forced expiratory volume in one second; PC20: provocative concentration of methacholine causing a 20\% fall in FEV1. *: grass-specific IgE was determined by DHA CLA Allergy test. 
cytometer (FACScan, Becton-Dickinson). In brief, $100 \mu \mathrm{L}$ of heparinized whole blood was incubated in the presence of saturating concentrations of fluorescein- or phycoerythrin-conjugated $\mathrm{mAB}$ at room temperature for $20 \mathrm{~min}$. Erythrocytes were lysed by adding $2 \mathrm{~mL}$ lysing solution for $10 \mathrm{~min}$. Cells were washed twice with phosphate-buffered saline containing $2 \%$ fetal calf serum and $0.1 \%$ sodium azide. Cytofluorimetric analysis was performed by imposing an electronic gate on forward-scatter and side-scatter dot plots for peripheral blood lymphocytes. The number of immunofluorescence-positive cells was determined in 10,000 analysed cells. Specific binding of mAB was controlled by subtraction of isotype-matched mouse immunoglobulins. mAB against CD3 (T-cells), CD4 (T-helperinducer), CD8 (T-suppressor-cytotoxic), CD19 (B-cells), CD25 (p55 IL-2 receptor), HLA-DR and CD23 (B-cells expressing the low-affinity $\mathrm{Fc}$ IgE receptor) were purchased from Becton-Dickinson.

Simultaneous T-cell subset analyses (CD4 and CD8) and activation studies (expression of activation markers CD25 and HLA-DR) were performed on peripheral blood lymphocytes.

\section{Data analysis}

Results were expressed as medians and range, or means \pm SEM when appropriate. In immunotherapy-treated patients, data before SIT were compared with results after SIT using Wilcoxon's signed rank test. The Mann-Whitney U-test was used to compare data between immununotherapy-treated patients and the control group. Correlations were examined by Spearman's rank correlation coefficient. A p-value of $<0.05$ was considered significant.

\section{Results}

All the patients with grass pollen-sensitive asthma completed the treatment period and no local or systemic sideeffects were reported.

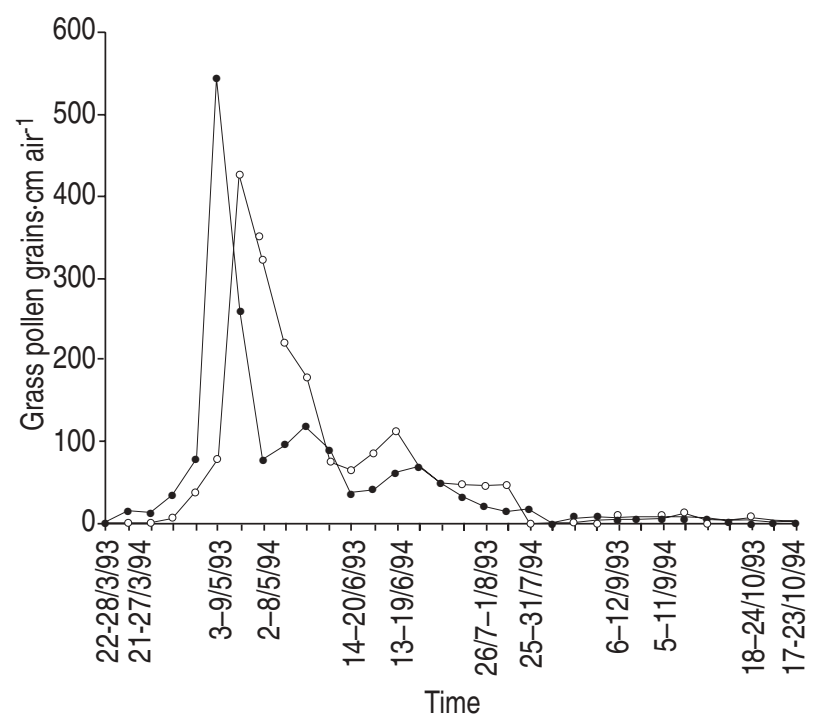

Fig. 1. - Average data on grass pollen gathered by Agenzia Regionale per la prevenzione e l'ambiente dell'Emilia Romagna, Sezione Provinciale di Parma, spring-summer 1993 (○) and spring-summer 1994 (•).
All subjects had mild symptomatic asthma (cough and/ or dyspnoea) only during the pollen season. The comparison of symptom scores and salbutamol consumption during P0 and P1 showed a statistically significant decrease for both symptom scores (from $4.3 \pm 0.5$ to $3.1 \pm 0.4, \mathrm{p}=$ 0.05 ) and salbutamol consumption (from 5.6 \pm 0.9 to $2.5 \pm$ 1.9, $\mathrm{p}=0.05)$. PEF data were not analysed because they were only available for seven patients.

Grass pollen counts in Parma were similar during the same periods (fig. 1). Grass-specific IgE levels were significantly reduced (from $3.75 \pm 0.13$ to $3 \pm 0.4$, p=0.01) where-as there were no significant differences in the FEV1 (from $99.5 \pm 3.3$ to $97.2 \pm 2 \%$ of predicted value, Ns) and methacholine sensitivity (from $4.99 \pm 0.87$ to $5.4 \pm 1 \mathrm{mg} \cdot \mathrm{mL}$ $1, \mathrm{NS})$ at T1 when compared to T0.

Flow cytometric analysis of peripheral blood lymphocytes at $\mathrm{T} 0$ and $\mathrm{T} 1$ showed no significant differences in the percentage of T-lymphocytes (CD3+) or B-lymphocytes (CD19+), nor was there any change in either the CD4+ or CD8+ T-cell subsets (table 2). However, a comparison of the two activation markers CD25 and HLA-DR showed significant reduction at $\mathrm{T} 1$ in both $\mathrm{CD} 4+(\mathrm{p}=$
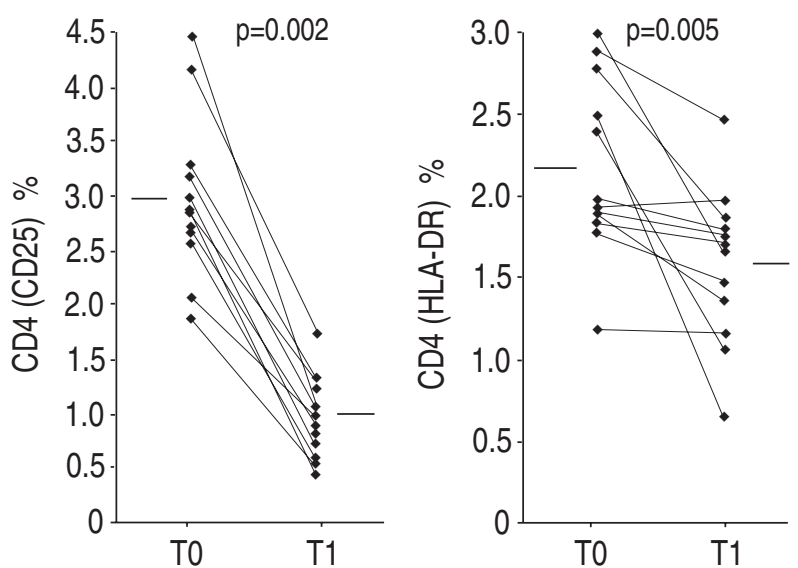

Fig. 2. - Percentages of peripheral blood CD4+ cells expressing the two activation markers, p55 interleukin-2 receptor (CD25) and human leukocyte antigen (HLA)-DR, from subjects with grass pollen-sensitive before (T0) and after (T1) specific immunotherapy. Horizontal bars represent group mean values.
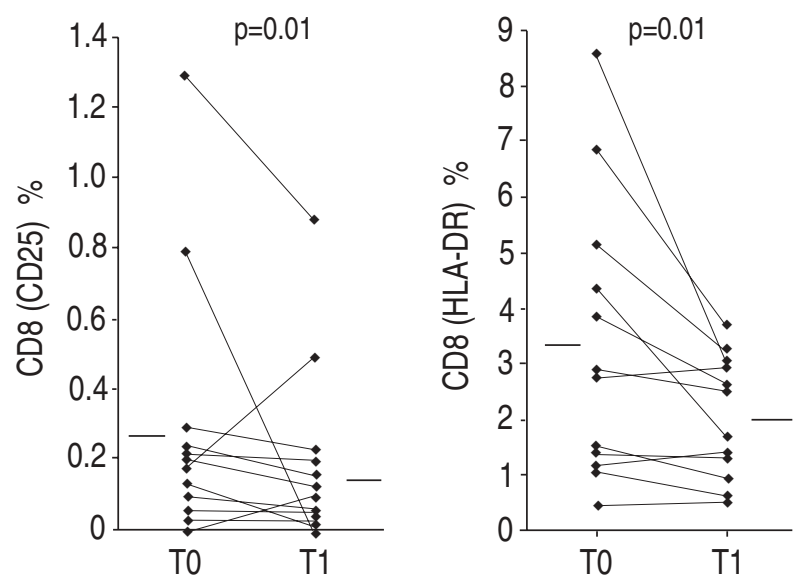

Fig. 3. - Percentages of peripheral blood CD8+ cells expressing the two activation markers, p55 interleukin-2 receptor (CD25) and human leukocyte antigen (HLA)-DR, from subjects with grass pollen-sensitive asthma before (T0) and after (T1) specific immunotherapy. Horizontal bars represent group mean values. 
Table 2. - Lymphocyte subpopulations from immunotherapy-treated patients and control group

\begin{tabular}{|c|c|c|c|c|c|c|c|c|c|}
\hline & CD3 & CD4 & $\mathrm{CD} 8$ & CD19 & $\mathrm{CD} 23$ & $\begin{array}{l}\text { CD4/ } \\
\text { CD25 }\end{array}$ & $\begin{array}{c}\text { CD4/ } \\
\text { HLA-DR }\end{array}$ & $\begin{array}{l}\text { CD8/ } \\
\text { CD25 }\end{array}$ & $\begin{array}{c}\text { CD8/ } \\
\text { HLA-DR }\end{array}$ \\
\hline \multicolumn{10}{|l|}{ Before SIT (A) } \\
\hline Median & 73.4 & 38.1 & 34.5 & 12.3 & 9.3 & 2.9 & 1.95 & 0.2 & 2.85 \\
\hline Range & $70.1-82.6$ & $30.2-55.6$ & $22.2-46.9$ & $5.5-22.1$ & $3.6-16.2$ & $1.9-4.5$ & $1.2-3.0$ & $0-1.3$ & $0.5-8.6$ \\
\hline \multicolumn{10}{|l|}{ After SIT (B) } \\
\hline Median & 73.2 & 35.9 & 37.2 & 9.6 & 7.1 & 1.0 & 1.75 & 0.1 & 2.2 \\
\hline Range & $59.9-79.4$ & $30.7-55.5$ & $22.4-46.0$ & $4.6-14.6$ & $3.6-10.8$ & $0.6-1.8$ & $0.7-2.5$ & $0-0.9$ & $0.6-3.8$ \\
\hline \multicolumn{10}{|l|}{ Controls (C) } \\
\hline Median & 72.2 & 42.0 & 32.1 & 9.6 & 8.6 & 2.8 & 1.9 & 0.2 & 2.9 \\
\hline Range & $53.3-87.8$ & $27.4-67.0$ & $20.5-55.9$ & $2.9-19.9$ & $2.0-15.4$ & $0.7-4.8$ & $1.2-3.7$ & $0.1-0.7$ & $1.3-7.0$ \\
\hline A versus B & NS & NS & NS & NS & $\mathrm{p}=0.008$ & $\mathrm{p}=0.002$ & $\mathrm{p}=0.005$ & $\mathrm{p}=0.01$ & $\mathrm{p}=0.01$ \\
\hline A versus $\mathrm{C}$ & NS & NS & NS & NS & NS & NS & NS & NS & NS \\
\hline B versus C & NS & NS & NS & NS & $\mathrm{p}=0.05$ & $\mathrm{p}=0.001$ & $\mathrm{p}=0.01$ & $\mathrm{p}=0.05$ & $\mathrm{p}=0.05$ \\
\hline
\end{tabular}

SIT: specific immunotherapy; ss: nonsignificant.

0.002 and $\mathrm{p}=0.005$, respectively) and $\mathrm{CD} 8+(\mathrm{p}=0.01$ and $\mathrm{p}=0.01$, respectively) T-cell subsets (figs. 2 and 3 ). Evaluation of B-cells expressing CD23 also demonstrated a significant reduction in $\mathrm{CD} 23+\mathrm{B}$-cells $(\mathrm{p}=0.008)$ (table 2) after 1 yr of SIT.

The decreased T-lymphocyte activation observed in immunotherapy-treated subjects after the treatment year was also significant in comparison to control group (table 2).

\section{Discussion}

This study showed a downregulation of CD4 and CD8 T-lymphocyte activation in parallel with a significant reduction in CD23+ B-cells and grass-specific IgE levels in the peripheral blood of subjects with grass pollen-sensitive asthma after $1 \mathrm{yr}$ of SIT. Moreover, the reduction in symptoms and need for drugs during the pollen season of the treatment year confirmed the clinical efficacy of SIT in grass pollen-sensitive asthma $[16,17]$.

Since this study examined peripheral blood T-cells in patients out of the pollen season, when they were clinically healthy subjects, it can only be presumed that the downregulation of T-lymphocyte activation in peripheral blood correlates with the clinical success of SIT, and it remains to be studied whether nonresponders to SIT lack similar changes in immunoreactivity to the injected allergen. Moreover, studying peripheral blood T-cells during the pollen season limits the reliability of the study because it has been demonstrated that exposure to artificial or natural antigens alters T-cell subsets $[18,19]$ or activation [20] in peripheral blood from allergic asthmatic subjects.

To the best of our knowledge, there have been no studies on the effect of SIT on T-lymphocyte activation in peripheral blood from subjects with grass pollen-sensitive asthma.

CD25 and HLA-DR are well-established markers of Tlymphocyte activation. The fact that SIT of the asthmatic patients was associated with a reduction in the percentages of peripheral blood CD4+ and CD8+ T-lymphocytes expressing these markers, but not a reduction in the overall numbers of these cells, suggests that SIT acted directly on these cells to reverse their activated status.

The production of allergen-specific $\operatorname{IgE}$ is under the control of activated T-cells through the release of cytokines such as IL-4, which stimulate B-cells to proliferate and to undergo isotype switching to produce IgE [21]. It can be speculated, therefore, that the decrease in CD23 expression on B-cells and in grass-specific IgE levels in the peripheral blood of asthmatic subjects after SIT may be a consequence of the downregulation of T-lymphocyte activation in the same compartment.

The downregulation of CD8 (other than CD4) T-lymphocyte activation may be important in view of the increasing evidence for the existence of Th2-like CD8+ T-cells [22-26]. It is now clear that CD8+ cells may also secrete cytokines such as IL-4 and IL-5, which are essential cofactors in $\operatorname{IgE}$ synthesis and the accumulation and activation of eosinophils, respectively [27, 28]. In this regard, WALKER et al. [29] demonstrated an upregulation of CD8 Tlymphocyte activation in bronchoalveolar lavage and peripheral blood of nonallergic asthmatics, and HAMELMANN et al. [30] demonstrated a critical role for CD8+ T-cells in the development of airway hyperresponsiveness in a murine model of airway sensitization.

In conclusion, this study shows a downregulation of peripheral lymphocyte activation in both CD4+ and CD8+ T-cell subsets in parallel with a significant decrease in CD23 expression on B-cells and in grass-specific immunoglobulin levels in subjects with grass pollen-sensitive asthma after $1 \mathrm{yr}$ of specific immunotherapy. These data add to view that the efficacy of specific immunotherapy may be attributed to the downregulation of T-cell responses.

Acknowledgements: The authors would like to thank E. de Young for help with the final text of this paper, I. Spanevello for expert technical assistance, F. Cassone for grass pollen counts and F. Gardini for statistical analysis.

\section{References}

1. Bousquet J, Hejjaoui A, Michel FB. Specific immunotherapy in asthma. J Allergy Clin Immunol 1990; 86: 292305.

2. Lichtenstein LM, Norman PS, Winkenwerden WL, Osler AG. In vitro studies of human ragweed allergy: changes in cellular and humoral activity associated with specific desensitization. J Clin Invest 1996; 45: 1126-1136.

3. Levy DA, Osler AG. Studies on the mechanism of hypersensivity phenomena. XVI. In vitro assays of reaginic activity in human sera: effect of therapeutic immunization on seasonal titer changes. J Immunol 1967; 99: 10681077. 
4. Castracane JM, Rocklin RE. Detection of human autoanti-idiotypic antibodies (Ab2). II. Generation of Ab2 in atopic patients undergoing allergen immunotherapy. Int Arch Allergy Appl Immunol 1988; 86: 295-302.

5. Evans R, Pence H, Kaplan H, Rocklin RE. The effect of immunotherapy on humoral and cellular responses in ragweed hayfever. J Clin Invest 1976; 57: 1378-1385.

6. Hsieh K. Altered IL-2 production and responsiveness after hyposensitization to house dust. J Allergy Clin Immunol 1985; 76: 188-195.

7. Rocklin RE, Sheffer AL, Greineder DK, Melmon KL. Generation of antigen-specific suppressor cells during allergy desensitization. $N$ Engl J Med 1980; 22: 12131219.

8. Varney VA, Hamid QA, Gaga M, et al. Influence of grass pollen immunotherapy on cellular infiltration and cytokine mRNA expression during allergen-induced late-phase cutaneous responses. J Clin Invest 1993; 92: 644-651.

9. Durham SR, Varney VA, Ying S, et al. Effect of grass pollen immunotherapy on cell infiltration and cytokine mRNA expression during allergen-induced late nasal responses. J Allergy Clin Immunol 1994; 93: 230.

10. Corrigan JC, Hamid QA, Kay AB. T lymphocytes and the pathogenesis of bronchial asthma: studies using the techniques of in situ hybridization and polymerase chain reaction cDNA amplification. In: Holgate ST, Austen KF, Lichtenstein LM, Kay AB, eds. Asthma: Physiology, Immunopharmacology and Treatment, Fourth International Symposium. London, Academic Press, 1996; pp. 153162.

11. Corrigan JC, Hartnell A, Kay AB. T-lymphocyte activation in acute severe asthma. Lancet 1988; 1: 1129-1132.

12. Corrigan JC, Haczku A, Gemou-Engesaeth V, et al. CD4 T-lymphocyte activation in asthma is accompanied by increased serum concentrations of interleukin-5. Effect of glucocorticoid therapy. Am Rev Respir Dis 1993; 147: 540-547.

13. Canonica GW, Dirienzo W, Cosulich E, Ferrini S, Ciprandi G, Melioli G. Abnormalities of circulating T cell subsets: influence of specific immunotherapy. Int Arch Allergy Appl Immunol 1983; 71: 300-303.

14. Bonno M, Fujisawa T, Iguchi $\mathrm{K}$, et al. Mite-specific induction of interleukin-2 receptor on $\mathrm{T}$ lymphocytes from children with mite-sensitive asthma: modified immune response with immunotherapy. J Allergy Clin Immunol 1996; 97: 680-688.

15. American Thoracic Society. Standards for the diagnosis and care of patients with chronic obstructive pulmonary disease (COPD) and asthma. Am Rev Respir Dis 1987; 136: 225-244

16. Bousquet J, Maasch HJ, Hejjaoui A, et al. Double-blind, placebo-controlled immunotherapy with mixed grass-pollen allergoids. III. Efficacy and safety of unfractionated and high-molecular-weight preparations in rhinoconjunctivitis and asthma. J Allergy Clin Immunol 1989; 84: $546-$ 556.
17. Bousquet J, Hejjaoui A, Soussana M, Michel FB. Double-blind, placebo-controlled immunotherapy with mixed-grass pollen allergoids. IV. Comparison of the safety and efficacy of two dosages of a high-molecular-weight allergoid. J Allergy Clin Immunol 1990; 85: 490-497.

18. Gerblich AA, Campbell AK, Schuyler MR. Changes in T-lymphocyte subpopulations after antigen bronchial provocation in asthmatics. N Engl J Med 1984; 310: 13491352.

19. Rak S, Hallden G, Sorenson S, Margari V, Scheynius A. The effect of immunotherapy on T-cell subsets in peripheral blood and bronchoalveolar lavage fluid in pollenallergic patients. Allergy 1993; 48: 460-465.

20. Majori M, Piccoli ML, Melej R, Pileggi V, Pesci A. Lymphocyte activation markers in peripheral blood before and after natural exposure to allergen in asthmatic patients. Respiration 1997; 64: 45-49.

21. Lebman DA, Coffman RL. Interleukin 4 causes isotype switching to IgE in T cell-stimulated clonal B cell cultures. J Exp Med 1988; 168: 853-862.

22. Salgame P, Abrams JS, Clayberger C, et al. Differing lymphokine profiles of functional subsets of human CD4 and CD8 T cell clones. Science 1991; 254: 279-282.

23. Romagnani S, Maggi E, Del Prete GF. An alternative view of the Th1/Th2 switch hypothesis in HIV infection. AIDS Res Hum Retroviruses 1994; 10: iii-ix.

24. Croft M, Carter L, Swain SL, Dutton RW. Generation of polarized antigen specific CD8 effector populations: reciprocal action of IL-4 and IL-12 in promoting type 2 versus type 1 cytokine profiles. J Exp Med 1994; 180: 17151728.

25. Sad S, Marcotte R, Mosmann TR. Cytokine-induced differentiation of precursor mouse $\mathrm{CD} 8+\mathrm{T}$ cells into cytotoxic CD8+ T cells secreting TH1 or TH2 cytokines. Immunity 1995; 2: 271-279.

26. Coyle AJ, Erard F, Bertrand C, Walti S, Pircher H, Le Gros G. Virus specific CD8+ cells can switch to IL-5 production and induce airway eosinophilia. J Exp Med 1995; 181: 1229-1233.

27. Del Prete GF, Maggi E, Parronchi P, et al. IL-4 is an essential cofactor for the IgE synthesis induced in vitro by human $\mathrm{T}$ cell clones and their supernatants. J Immunol 1988; 140: 4193-4198.

28. Lopez AF, Sanderson CJ, Gamble JR, Campbell HD, Young IG, Vadas MA. Recombinant human interleukin-5 is a selective activator of human eosinophil function. $J$ Exp Med 1988; 167: 219-224.

29. Walker C, Bode E, Boer L, Hansel TT, Blaser K, Virchow JC. Allergic and nonallergic asthmatics have distinct patterns of T-cell activation and cytokine production in peripheral blood and bronchoalveolar lavage. Am Rev Respir Dis 1992; 146: 109-115.

30. Hamelmann E, Oshiba A, Paluh J, et al. Requirement for $\mathrm{CD} 8+\mathrm{T}$ cells in the development of airway hyperresponsiveness in a murine model of airway sensitization. $J$ Exp Med 1996; 183: 1719-1729. 